Though highly effective in treating $P$ falciparum and $P$ vivax malaria, atovaquone/proguanil has poor outcome in $P$ vivax malaria when used alone. The drug combination has no effect on hypnozoites of $P$ vivax, thus leading to high relapse rates $(>75 \%)$. However, if primaquine is given daily for 14 days following completion of atovaquone/proguanil therapy in $P$ vivax malaria, most patients remain free of parasitemia during the follow-up period.

The usefulness of atovaquone/proguanil has also been demonstrated in multi-drug resistant malaria. In a study conducted in Thailand, $97.8 \%$ of the 140 multi-drug resistant $P$ falciparum cases responded to therapy and remained clear of parasitemia at follow-up [5]. Atovaquone/proguanil is highly effective for prophylaxis against malaria and is now recommended as a prophylactic alternative to mefloquine or doxycycline in chloroquine-resistant areas.

\section{Adverse Effects}

At the doses employed for the treatment of malaria, adverse reactions with atovaquone/proguanil have been mild. The common adverse effects are abdominal pain $(17 \%)$, nausea $(12 \%)$, vomiting $(12 \%)$, headache $(10 \%)$, diarrhoea $(8 \%)$, asthenia $(8 \%)$, pruritus $(6 \%)$, anorexia $(5 \%)$, and dizziness $(5 \%)$. The rare adverse reactions include anaphylaxis, angioedema, phototoxicity, StevensJohnson syndrome, erythema multiforme, hallucinations, seizures and hepatitis. Atovaquone/proguanil is better tolerated than chloroquine or sulfadoxine/pyrimethamine. Although recent studies in pregnant women have shown the regimen to be well tolerated with no evidence of toxicity to the mother or foetus, further studies are needed before its safety during pregnancy can be fully established.

\section{Emergence of Resistance}

Recent studies have shown that resistance may emerge during therapy with atovaquone/proguanil. This suggests that the synergistic interaction between the two drugs is lost following mutations in the parasite cytochrome B. Several factors may contribute to emergence of resistance, including high parasite burdens, rapid metabolism of proguanil, exposure to suboptimal drug concentrations, or prior exposure to related drugs.

\section{Conclusion}

Atovaquone/proguanil may well become the first line drug combination in the treatment and prophylaxis of malaria, due to its excellent safety profile and the oral route of administration.

\section{Conflicts of Interest}

None identified

\section{References}

1. Kevin SG, Linda SL, Sonja M, Monica EP. Treatment of malaria in the United States: A systematic review. JAMA 2007; 297: 2264-77.

2. McKeage K, Scott LJ. Atovaquone/proguanil. Drugs 2003; 63: 597-623.

3. Marra F, Ensom M, Salzman J. Atovaquone/proguanil for prophylaxis and treatment of malaria. Annals of Pharmacotherapy 2005; 37: 1266-75.

4. Uchiyama H, Okamoto A, Sato K. Quinine-resistant severe falciparum malaria effectively treated with atovaquone and proguanil hydrochloride combination therapy. Intern Med 2004; 43: 624-7.

5. Krudsood S, Patel SN, Tangpukdee N, Thanachartwet W. Efficacy of atovaquone/proguanil for treatment of acute multidrug-resistant Plasmodium falciparum malaria in Thailand. Am J Trop Med Hyg 2007; 76: 655-8.

\title{
ERRATUM
}

1. Update Article: Prostate Cancer -What's New? MJAFI 2008;64:51-6. In first line under paragraph Screening on page 54:-

For: The incidence of $\mathrm{CaP}$ in Asia and India (4.8-8 cases per lac population versus 140 per lac population) is more than ten times than that in USA and Europe.

Read: The incidence of $\mathrm{CaP}$ in Asia and India (4.8-8 cases per lac population versus 140 per lac population) is less than ten times than that in USA and Europe.

2. Case Report: A Case of Intramedullar Epidermoid Cyst. MJAFI 2008;64:72-3.

Title for : Intramedullar, Read: Intramedullary

For Authors: Lt Col MN Swamy, Read: Lt Col MN Swamy, Classified Specialist (Surgery \& Neurosurgery), Brig PK Sahoo, Consultant (Surgery \& Neurosurgery), Surg Cdr KI Mathai, Classified Specialist (Surgery \& Neurosurgery), Lt Col GV Ramdas, Classified Specialist (Surgery \& Neurosurgery), Lt Col K Prabhakaran, Classified Specialist (Anaesthesiology), Command Hospital (SC), Pune and Lt Col K Sahai, Classified Specialist (Pathology), Armed Forces Medical College, Pune.

3. Original Article : Cost-effectiveness Analysis For Technology Acquisition. MJAFI 2008;64: 46-9 In Table 2 on page 48, under Present Value Benefit in $1^{\text {st }}$ year ; For : 13527408, Read : 0 and under Present Value Cost For : Nil, Read : 1,35,27,408 